\title{
Comparison of serological methods with PCR-based methods for the diagnosis of community-acquired pneumonia caused by atypical bacteria
}

Mariana Herrera ${ }^{1,2}$, Yudy Alexandra Aguilar ${ }^{1,2}, Z_{\text {Zulma Vanessa Rueda }}^{3}$, Carlos Muskus ${ }^{4}$ and Lázaro Agustín Vélez ${ }^{1,5^{*}}$

\begin{abstract}
Background: The diagnosis of community-acquired pneumonia (CAP) caused by Legionella pneumophila, Mycoplasma pneumoniae, and Chlamydophila pneumoniae is traditionally based on cultures and serology, which have special requirements, are time-consuming, and offer delayed results that limit their clinical usefulness of these techniques. We sought to develop a multiplex PCR (MPCR) method to diagnosis these bacterial infections in CAP patients and to compare the diagnostic yields obtained from MPCR of nasopharyngeal aspirates (NPAs), nasopharyngeal swabs (NPSs), and induced sputum (IS) with those obtained with specifc PCR commercial kits, paired serology, and urinary antigen.
\end{abstract}

Results: A total of 225 persons were included. Of these, 10 patients showed serological evidence of L. pneumophila infection, 30 of M. pneumoniae, and 18 of C. pneumoniae; 20 individuals showed no CAP. The sensitivities were mPCR-NPS $=23.1 \%$, mPCR-IS $=57.1 \%$, Seeplex ${ }^{\oplus}-1 S=52.4 \%$, and Speed-oligo ${ }^{-}$NPA/NPS $=11.1 \%$, and the specificities were mPCR-NPS $=97.1 \%$, mPCR-IS $=77.8 \%$, Seeplex ${ }^{\oplus}-1 S=92.6 \%$, and Speed-oligo ${ }^{\oplus}$-NPA/NPS $=96.1 \%$. The concordance between tests was poor (kappa $<0.4$ ), except for the concordance between MPCR and the commercial kit in IS (0.67). In individuals with no evidence of CAP, positive reactions were observed in paired serology and in all PCRs.

Conclusions: All PCRs had good specificity but low sensitivity in nasopharyngeal samples. The sensitivity of mPCR and Seeplex $x^{\circledast}$ in IS was approximately $60 \%$; thus, better diagnostic techniques for these three bacteria are required.

Keywords: M. pneumoniae, L. pneumophila, C. pneumoniae, Multiplex PCR, Atypical pneumonia, Molecular diagnosis

\section{Background}

Infections by the atypical bacteria Mycoplasma pneumoniae, Chlamydophila pneumoniae, and Legionella pneumophila are frequent causes of community-acquired pneumonia (CAP) in both children and adults [1-3]. Latin America has reported CAP figures caused by these bacteria ranging from 1.7 to $15.7 \%$ for $M$. pneumoniae,

\footnotetext{
* Correspondence: velezlazaro@yahoo.com

1 Grupo Investigador de Problemas en Enfermedades Infecciosas (GRIPE), Sede de Investigación Universitaria, Calle 62 \# 52-59, Laboratorio 630, Universidad de Antioquia, Medellín, Colombia

${ }^{5}$ Infectious Disease Section, School of Medicine, Universidad de Antioquia UdeA, Medellín, Colombia

Full list of author information is available at the end of the article
}

3.4 to $6.1 \%$ for C. pneumoniae, and 1.1 to $4 \%$ for $L$. pneumophila $[3,4]$.

Diagnosis of these bacteria is traditionally based on cultures and serology, which involve special technical requirements that are costly and time-consuming, offer delayed results, and in the case of serology, require a second convalescent-phase sample, which limits the clinical usefulness of these techniques [5-7]. This explains why although the circulation of atypical bacteria in the region is evident, these bacteria can only be diagnosed in very specialized reference centers. Due to this aspect, and because the clinical presentation does not differ significantly from that caused by pyogenic bacteria or respiratory viruses [8], the perception is that these agents 
are rare in these countries. The therapeutic consequence of this omission is the prescription of insufficient treatments in some cases or treatments that are excessive and unnecessary in others.

Given these problems, nucleic acid amplification techniques are often used, including conventional PCR, realtime PCR (qPCR), and in-house or commercial mPCR [9-11]. These are considered faster, more sensitive, and more specific than cultures and serology [12]. However, the possibility of contamination and the difficulties of interpreting positive cases as disease or colonization are the main limitations. Although several commercial kits for the detection of M. pneumoniae, C. pneumoniae, and L. pneumophila are now available [10,13-15], limited information is available in the literature regarding the validation process of such tests. The existing studies have limited information about the clinical condition of the study population in which the tests were validated, the samples used, and the molecular targets; some studies compared only the commercial kit with another inhouse or commercial molecular test, without using any other accepted reference tests (culture or paired serology). Additional file 1 describes the heterogeneity of the previously conducted studies.

To investigate a possible solution to these diagnostic difficulties, our aim was to standardize and validate an in-house MPCR for a quick and timely diagnosis of CAP caused by these atypical bacteria in a single reaction. In addition, we sought to evaluate the diagnostic performance of $\mathrm{mPCR}$ in different respiratory samples, namely, nasopharyngeal aspirates (NPAs), nasopharyngeal swabs (NPSs) and induced sputum (ISs), and to compare this performance with that of existing PCR commercial kits, paired serology, and urinary antigen.

\section{Results}

\section{Standardization of multiplex PCR}

The primers used allowed the amplification of the gene fragments of interest: mip from L. pneumophila, pstI from $C$. pneumoniae and $p 1$ from $M$. pneumoniae, and these primers showed no cross-reactions among the bacteria, either with related species or other microorganisms, according to the specificity analysis of the reaction obtained with the BLAST program. The conditions, under which optimal mPCR amplification was achieved in a final volume of $25 \mu \mathrm{L}$, were $0.05 \mathrm{U} / \mu \mathrm{L}$ Taq polymerase (Fermentas St. Leon-Rot, Germany), 1X Taq buffer with $\mathrm{KCl}, 2.0 \mathrm{mM} \mathrm{MgCl}, 0.2 \mathrm{mM}$ dNTPs, $0.3 \mu \mathrm{M}$ concentrations of each primer, $0.1 \mathrm{mg} / \mu \mathrm{L}$ BSA, and $6 \mu \mathrm{L}$ of DNA (The median concentration of the extracted DNA from each sample was $4.9 \mathrm{ng} / \mu \mathrm{L}$, upper limit: $166.18 \mathrm{ng} / \mu \mathrm{L}$, lower limit: $2.11 \mathrm{ng} / \mu \mathrm{L})$. The cycling conditions in the C1000 thermal cycler (BioRad, CA, USA) were as follows: one cycle of DNA denaturation at $95{ }^{\circ} \mathrm{C}$ for $5 \mathrm{~min} ; 35$ cycles of denaturation at $94{ }^{\circ} \mathrm{C}$ for $45 \mathrm{~s}$, primer annealing at $58{ }^{\circ} \mathrm{C}$ for $60 \mathrm{~s}$ and primer extension at $72{ }^{\circ} \mathrm{C}$ for $45 \mathrm{~s}$; and a final extension at $72{ }^{\circ} \mathrm{C}$ for $7 \mathrm{~min}$.

Standardized PCR had a detection limit of 375 copies for each gene, regardless of whether the PCR was set-up to amplify a single gene or two or three genes simultaneously (Fig. 1); however, some amplification was observed with 187 copies of DNA, especially when a DNA mixture of two bacterial strains was run. No cross-amplification with DNA from the 17 different pathogens and/or colonizing microorganisms of the respiratory tract or with human DNA (Fig. 2) was observed.

Standardized mPCR was reproducible using a concentration of 750 copies of each gene when six PCR reactions were run simultaneously (intra-assay reproducibility) and on six different days (interassay reproducibility). Regardless of the test day, the intensity of the signal did not vary.

\section{Clinical and epidemiological characteristics}

A total of 205 individuals with CAP were analyzed in three groups - 68 adults in Group 1, 88 adults in Group 2 and 49 children in Group 3. Table 1 describes the main characteristics of these three groups. The etiology observed in Table 1 does not reflect the percentage distribution of the microorganisms found in the evaluated cohorts but is due to the selection of patients required to evaluate the techniques being studied.

Most of the 20 individuals in group 4 (control group) were male $(60 \%)$ and had a median age of 50 years (Q1 to $\mathrm{Q} 3=29$ to 55 ). Eight of the 10 individuals who suffered rheumatic diseases had been diagnosed with rheumatoid arthritis; 1 , with systemic lupus erythematosus; and 1, with Sjögren's syndrome. Three of them were receiving tumor necrosis factor-alpha (anti-TNF $\alpha$ ) antagonists at the time of inclusion in the study.

\section{Test results}

Among the 225 patients included in the 4 groups, 190 paired serologies were performed (46 in group 1, 77 in group 2, 48 in group 3, and 19 in group 4). In addition, $88 \mathrm{mPCR}$ were performed in NPAs, $137 \mathrm{mPCR}$ in NPSs, $49 \mathrm{mPCR}$ and 49 Seeplex ${ }^{\circ}$ Pneumobacter in IS, and 161 Speed-Oligo ${ }^{\circ}$ in NPAs or NPSs. The L. pneumophila urinary antigen was positive in only one patient in group 2, who also exhibited a positive paired serology; because of that, this urinary antigen was not considered as a gold standard.

The results of the negative and positive controls of the serology tests, the urinary antigen and the different molecular tests were always negative and positive, respectively. The inhibition control of the PCRs was positive in all samples tested, indicating the absence of PCR inhibitors. 


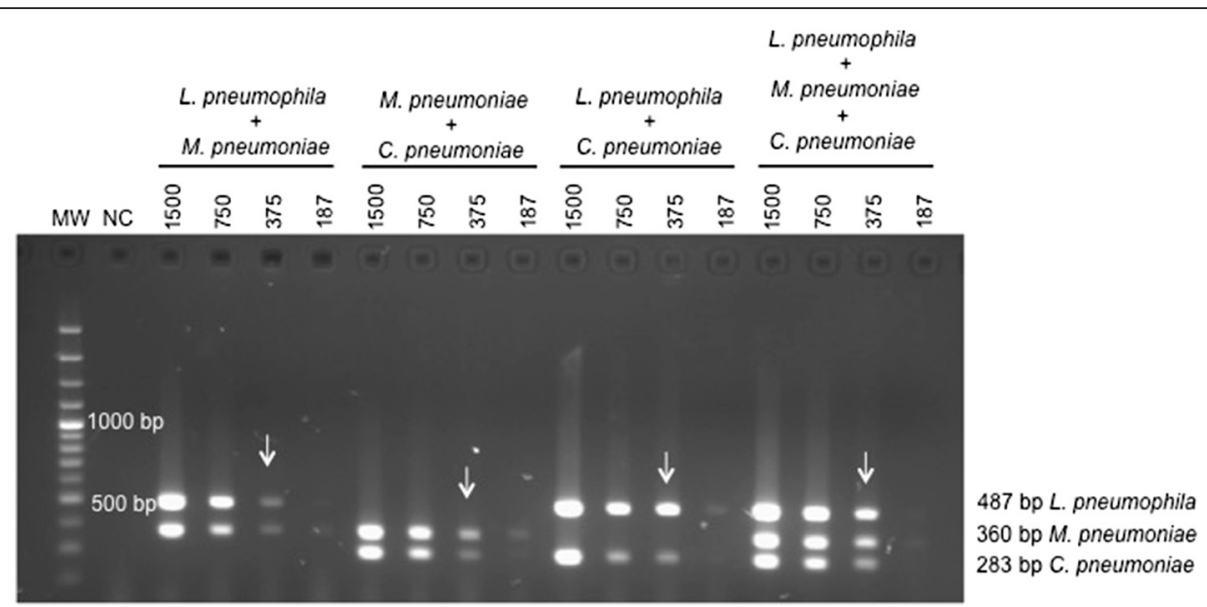

Fig. 1 Analytical sensitivity of mPCR using 1,500; 750; 375; and 187 copies of L. pneumophila mip genes, p1 of M. pneumoniae, and Pstl of C. pneumoniae MW: 100 bp molecular weight marker; NC: negative control; Lines marked with arrows correspond to the amplicons from 375 copies of each gene

In samples obtained from hospitalized patients showing CAP symptoms and distributed among groups 1, 2 and 3, mPCR was only positive for M. pneumoniae in one sample in group 1 and in 25 samples of group 3 (7 samples of NSP and 18 IS samples). No amplification was observed for C. pneumoniae and L. pneumophila in any of the samples with mPCR. In contrast, with commercial PCR (Speed-oligo or Seeplex), amplification was achieved in a larger number of samples undergoing mPCR. With commercial PCR, a total of 18 M. pneumoniae-positive samples were detected in the three groups (4 in group 1, 1 in group 2, and 13 in the group 3). Only 1 sample in group 2 was positive for C. pneumoniae, and 2 samples in group 1 were positive for $L$. pneumophila (Table 2).

When assessing the positivity of serology by quadrupling the antibody titers, the technique considered the gold standard in this study, serology was observed to detect a greater number of positive samples than any of the 3 types of PCR used in this study. For $M$. pneumonia, 30 samples were positive (5 in group 1, 4 in the group 2, and 21 in the group 3). For C. pneumoniae, 18 samples were positive ( 3 in group 1,9 in group 2, and 6 in group 3), whereas 10 samples were positive for L. pneumophila, (3 in group 1, 2 in group 2 , and 5 in group 3). In group 3, two types of samples (NPSs and IS) were evaluated by mPCR. Only the presence of DNA from M. pneumonia was detected in 25 samples. Of these, 18 samples were positive for the IS, and 7, for the NPSs.

Interestingly, in samples from the control group and without symptoms of CAP, 6 serologically positive samples were detected. Of these, 2 were positive for $M$. pneumoniae, and 4, for C. pneumoniae. In addition, one sample was positive for mPCR, and 4 , for commercial PCR for L. pneumophila.

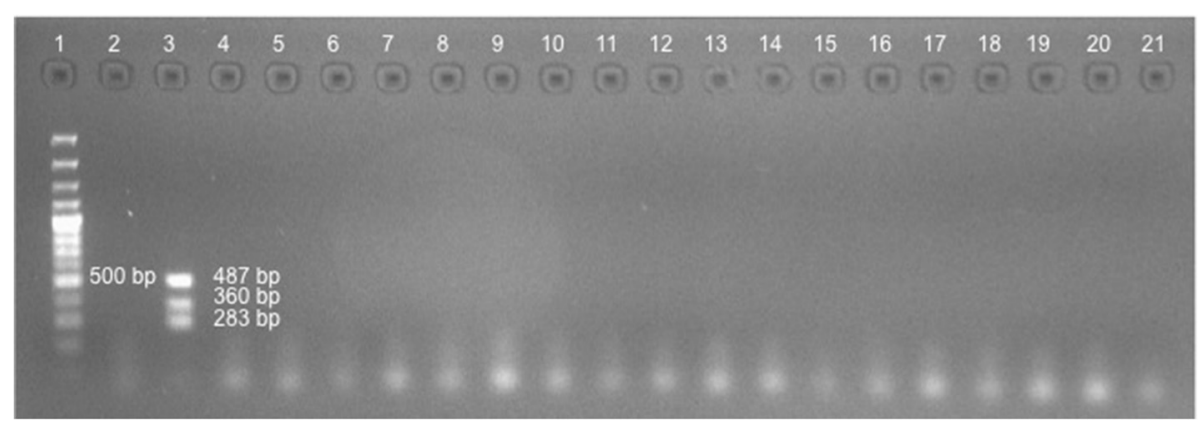

Fig. 2 Analytical specificity of mPCR. 1. Molecular weight marker 100 bp; 2. Negative control; 3. Positive control (487 bp L. pneumophila, 360 bp M. pneumoniae, and 283 bp C. pneumoniae); Bacteria: 4. Streptococcus pneumoniae; 5. Haemophilus influenzae; 6 . Klebsiella pneumoniae; 7. Escherichia coli; 8. Pseudomonas aeruginosa; 9. Staphylococcus aureus; 10. Nocardia spp.; 11. Enterobacter cloacae; Fungi: 12. Histoplasma capsulatum; 13. Aspergillus terreus; 14. Cryptococcus neoformans; 15. Candida tropicalis; 16. Candida albicans; 17. Candida guilliermondii; 18. Candida glabrata; 19. Paracoccidioides brasiliensis; 20. Mycobacterium tuberculosis (bacteria); 21. Human DNA 
Table 1 Clinical and epidemiological characteristics of the population with CAP

\begin{tabular}{|c|c|c|c|}
\hline Variables & $\begin{array}{l}\text { Group } 1 \\
(n=68)\end{array}$ & $\begin{array}{l}\text { Group } 2 \\
(n=88)\end{array}$ & $\begin{array}{l}\text { Group } 3 \\
(n=49)\end{array}$ \\
\hline Age in years, Median $\left(Q_{1}-Q_{3}\right)$ & $65(41-76)$ & $63(40-76)$ & $3(1-7)$ \\
\hline Males, n (\%) & $28(41.2)$ & $49(55.7)$ & $29(59.2)$ \\
\hline Received antibiotics in last 3 months, n (\%) & $19(27.9)$ & $10(11.4)$ & $9(18.4)$ \\
\hline Symptom duration, in days, Median $\left(\mathrm{Q}_{1}-\mathrm{Q}_{3}\right)$ & $7(4-15)$ & $6(3-10)$ & $4(2-8)$ \\
\hline Presence of comorbidities, n (\%) & $37(54.4)$ & $50(56.8)$ & $2(4.1)$ \\
\hline Chronic obstructive pulmonary disease & $24(35.3)$ & $37(42)$ & 0 \\
\hline History of convulsions in the last month & 0 & $3(3.4)$ & $2(4.1)$ \\
\hline Severe pneumonia ${ }^{a}, \mathrm{n}(\%)$ & $15(22.1)$ & $26(29.5)$ & $1(2.0)$ \\
\hline \multicolumn{4}{|l|}{ Frequency of atypical bacteria, n (\%) } \\
\hline M. pneumoniae & $5(10.9)$ & $4(5.2)$ & $21(43.8)$ \\
\hline C. pneumoniae & $3(6.5)$ & $9(11.7)$ & $6(12.5)$ \\
\hline L. pneumophila & $3(6.5)$ & $2(2.6)$ & $5(10.4)$ \\
\hline Length of hospital stay, in days, Median $\left(\mathrm{Q}_{1}-\mathrm{Q}_{3}\right)$ & $6(3-9)$ & $7(4-10)$ & $4(2-9)$ \\
\hline In-hospital death, n (\%) & 0 & $8(9.1)$ & 0 \\
\hline
\end{tabular}

${ }^{\mathrm{a}}$ In children (group 3), this corresponds to the WHO classification of very severe pneumonia

Finally, when analyzing the samples obtained from individuals with CAP in a global and comprehensive manner, that is, without division by groups, M. pneumoniae was the most detected bacteria by any of the three methods. By serology, 30 samples were detected, and by mPCR, 26 samples, whereas 18 samples were positive by CPCR. For C. pneumoniae, only one sample was positive by $\mathrm{CPCR}$, and 18 were positive by serology, whereas for L. pneumophila, 2 samples were positives by $\mathrm{CPCR}$, and 10 , by serology (Table 2 ).
Given that no positive cases of C. pneumoniae and $L$. pneumophila were obtained by $\mathrm{mPCR}$, and very few cases, by commercial PCR, only the operating characteristics of the PCRs to M. pneumoniae are presented below.

Table 3 shows that the PCRs exhibit high specificity with low sensitivity in the nasopharyngeal samples for both the NPAs and NPSs. The sensitivity was higher in the IS, but was only $57.1 \%$ for mPCR and $52.4 \%$ for Seeplex ${ }^{\circ}$ PneumoBacter. In turn, when the PCRs with

Table 2 Positive results of serology, in-house mPCR, and commercial PCR classified by atypical bacteria

\begin{tabular}{|c|c|c|c|c|}
\hline Techniques & $\begin{array}{l}\text { Group } 1^{a} \\
\text { NPS }\end{array}$ & $\begin{array}{l}\text { Group } 2^{b} \\
\text { NPA }\end{array}$ & $\begin{array}{l}\text { Group } 3^{c} \\
\text { NPS and IS }\end{array}$ & $\begin{array}{l}\text { Group } 4^{d} \\
\text { NPS }\end{array}$ \\
\hline M. pneumoniae & n (\%) & n (\%) & n (\%) & n (\%) \\
\hline Serology & $5 / 46(10.9)$ & 4/77 (5.2) & 21/48 (43.8) & $2 / 19(10.5)$ \\
\hline $\mathrm{mPCR}$ & $1 / 68(1.5)$ & 0/88 (0) & NPS: 7 (14.3)IS: 18 (36.7) & $0 / 20(0)$ \\
\hline $\begin{array}{l}\text { Commercial PCR } \\
\text { [Trade mark] }\end{array}$ & $\begin{array}{l}\text { 4/68 (5.9) } \\
\text { [Speed-oligo] }\end{array}$ & $\begin{array}{l}\text { 1/88 (1.4) } \\
\text { [Speed-oligo] }\end{array}$ & $\begin{array}{l}\text { 13/49 (26.5) } \\
\text { [Seeplex] }\end{array}$ & $\begin{array}{l}0 / 20(0) \\
\text { [Speed-oligo] }\end{array}$ \\
\hline \multicolumn{5}{|l|}{ C. pneumoniae } \\
\hline Serology & $3 / 46(6.5)$ & 9/77 (11.7) & $6 / 48(12.5)$ & $4 / 19(21.1)$ \\
\hline $\mathrm{mPCR}$ & 0/68 (0) & 0/88 (0) & NPS: 0 (0)IS: 0 (0) & $0 / 20(0)$ \\
\hline Commercial PCR & $0 / 68(0)$ & $1 / 88(1.4)$ & $0 / 49(0)$ & $0 / 20(0)$ \\
\hline \multicolumn{5}{|l|}{ L. pneumophila } \\
\hline Serology & $3 / 46(6.5)$ & 2/77 (2.6) & $5 / 48(10.4)$ & 0/19 (0) \\
\hline $\mathrm{mPCR}$ & 0/68 (0) & 0/88 (0) & NPS: 0 (0)IS: 0 (0) & $1 / 20(5.0)$ \\
\hline Commercial PCR & $2 / 68(2.9)$ & 0/88 (0) & $0 / 49(0)$ & $4 / 20(21)$ \\
\hline
\end{tabular}

NPS Nasopharyngeal swab, NPA Nasopharyngeal aspirate, IS Induced sputum

${ }^{\text {a }}$ Prospective adults with community-acquired pneumonia (CAP). Speed-Oligo ${ }^{\oplus}$ was run as commercial PCR on the NPSs

${ }^{\mathrm{b}}$ Retrospective adults with CAP. Speed-Oligo ${ }^{\circledR}$ was run as commercial PCR on the NPAs

${ }^{\circ}$ Children with CAP. Seeplex ${ }^{\oplus}$ PneumoBacter was run as a commercial PCR on IS

${ }^{\mathrm{d}}$ Individuals without CAP. Speed-oligo ${ }^{\circledast}$ was run as a commercial PCR on NPSs 
Table 3 Operational features of the PCRs used for M. pneumoniae

\begin{tabular}{lllll}
\hline Test (N) & Sensitivity (\%) & Specificity (\%) & PPV (\%) & NPV (\%) \\
\hline mPCR NPA (77) & N/A & N/A & N/A & N/A \\
mPCR NPS (94) & $23.1(4.9-41.2)$ & $97.1(92.3-100)$ & $75(38.7-100)$ & $76.7(67.2-86.2)$ \\
mPCR IS (48) & $57.1(33.6-80.7)$ & $77.8(60.2-95.3)$ & $66.7(42.1-91.2)$ & $70(51.9-88.1)$ \\
Seeplex ${ }^{\oplus}$ PneumoBacter IS (48) & $52.4(28.6-76.1)$ & $92.6(80.7-100)$ & $84.6(61.2-100)$ & $71.4(55.0-87.8)$ \\
Speed-oligo NPA/NPS (111) & $11.1(0-37.2)$ & $96.1(91.8-100)$ & $20(0-65.1)$ & $92.4(86.9-97.9)$
\end{tabular}

Values calculated with paired serologists as the gold standard. NPA Nasopharyngeal aspirate. NPS Nasopharyngeal swab. IS Induced sputum. PPV Positive predictive value. NPV Negative predictive value. N/A Not applicable (these values cannot be calculated for this test due to the lack of positive results in serology that coincide with the positive results in MPCR of NPAs)

the highest sensitivity in IS were compared with each other, PCR Seeplex ${ }^{\circ}$ PneumoBacter exhibited higher specificity and positive predictive value than $\mathrm{MPCR}$.

Under our PCR conditions, the concordance between methods in a single sample and between samples with a single method was very low (kappa coefficient $<0.4$ ). Interestingly, in the IS, the concordance was better between $\mathrm{mPCR}$ and Seeplex $(\mathrm{kappa}=0.67)($ Fig. 3).

\section{Discussion}

The results of this study allow us to highlight three key aspects: 1) the in-house PCR standardized in this study and the commercial PCRs used had low sensitivity and poor concordance compared with the paired serology; 2) the IS sample had the best performance for the diagnosis of $M$. pneumoniae by PCR compared with those obtained by NPAs and NPSs; and 3) the quadrupling of titers in the paired serology for C. pneumoniae and M. pneumoniae could occur in individuals without CAP. Among them, PCRs could also be positive for L. pneumophila.
Regarding the first point, the literature has reported good agreement between the in-house and commercial PCRs performed on sputum, bronchoalveolar lavage (BAL), and endotracheal aspirates with paired serology results [16]; however, in our study, the concordance between the evaluated PCRs and serology was very low. Templeton et al. reported similar findings in 2003; they found that out of 106 samples tested, 12 were positive by 3 methodologies other than PCR, but only 8 of these were positive by paired serology [17]. The finding of positive PCRs in respiratory secretions without quadrupling in antibody titers in patients with CAP may occur because these patients are asymptomatic carriers of $M$. pneumoniae or C. pneumoniae in the respiratory epithelium or because of the persistence of these bacteria or their nucleic acids in the respiratory tract following previous infections [18-20]. Similarly, the false negative results of PCRs could be explained by a bacterial load below the detection limit of the PCRs, previous antibiotic treatment in patients, dilutions of samples when added to the transport medium, degradation of

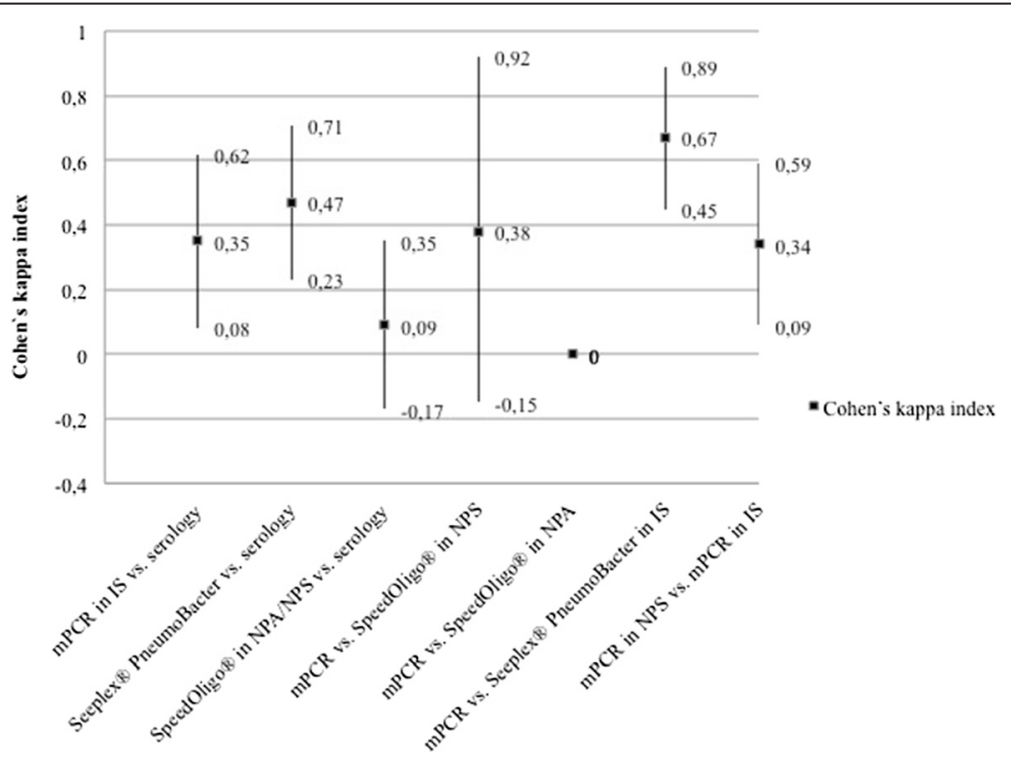

Fig. 3 Concordance (kappa index) between in-house (mPCR) and commercial PCR for Mycoplasma pneumoniae. NPS: Nasopharyngeal swab; NPA: Nasopharyngeal aspirate; IS: Induced sputum 
significant amounts of DNA during the sample storage process, or the presence of interfering DNA coming from human cells or other colonizing microorganisms of the respiratory tract, which would affect amplification. The positive and negative results in the controls in all experiments (serology, urinary antigen, and molecular techniques) ruled out the possibility of experimental error, and the amplification of the inhibition controls ruled out the presence of PCR inhibitors.

With regard to the sensitivity obtained for in-house mPCR and commercial kits using the quadrupling of titers in paired serology as the gold standard, this was lower than previous studies $[15,21]$, in which the sensitivity ranged from 66.7 to $97.3 \%$. Even sensitivities and specificities of up to $100 \%$ have been described when the gold standard used was a PCR monoplex assay and the study population was comprised solely of positive individuals confirmed by this technique [22] (53). This feature highlights the importance of knowing the characteristics of the study population, the type of respiratory sample being used (sputum, NPS, NPA, or BAL) and the inhibitors potentially present in each of them, the population where the PCR (adults, children, or elderly) is being assessed, and the various molecular targets being used.

NPSs and NPAs have been proposed as good choices of sample type for the diagnosis of CAP when resorting to non-invasive samples [23], but for the diagnosis of atypical bacteria, sputum has a higher performance than NPSs [24, 25], and in turn, these samples are superior to NPAs [26]. The results of our study were consistent with this claim; that is, we found that the PCR results varied for the diagnosis of $M$. pneumoniae depending on the type of respiratory specimen used, as the IS enabled the identification of a greater number of cases. In this regard, Collier and Clyde [27] and Kenny et al. [28] indicated that sputum samples were superior for the detection of $M$. pneumoniae because the number of bacteria are higher in the pulmonary alveolus than in the epithelium of the upper respiratory tract of patients with pneumonia. However, Reznikov et al. [26] reported that the PCR for M. pneumoniae in NPAs and NPSs had similar positivity percentages (45 and $50 \%$, respectively) but a greater presence of inhibitors in NPAs (36\%) than in NPSs $(0 \%)$.

The type of population also affects the operational features of the PCRs in that the results of paired serology vary according to patient age, prior exposure to these bacteria, or the presence of comorbidities. Acute $M$. pneumoniae infections in children are characterized by significant increases in $\operatorname{IgM}$ antibodies but can only increase titers of IgG or both immunoglobulins; also, the IgM titers may remain high for several months or even years [29], which constitutes the main limitation of this test. However, adults can respond by increasing only IgG, especially when a re-infection occurs by this germ, or they may be unable to mount an appropriate serological response due to deficiencies in the immune system, which are common in patients of certain ages [30] or with underlying diseases. Examples include immunocompromised individuals or those with rheumatologic diseases [31]. Therefore, the gold standard against which these molecular diagnostic techniques are being assessed is far from being the ideal test. Furthermore, PCR detection of atypical bacteria also has limitations; no consensus exists regarding which molecular target should be amplified to achieve higher sensitivity and specificity, nor does a clearly defined standard protocol exist [21, 32-34]. Depending on the selected molecular target, in which one or multiple copies could be in the investigated genome, the amount of DNA of the microorganisms present in the sample can vary significantly. Even when the presence of the same gene is studied using two different molecular tests, such as Speed-oligo and $\mathrm{mPCR}$, the results may show poor consistency. This may be due to differences in the methodologies used (including the type of PCR - monoplex versus multiplex - and the revealing technique - oligochromatography versus agarose gel electrophoresis) or because of the amplification of the different regions of the same gene [16]. Although some authors reported similar results when they used a single PCR or a duplex assay to detect two of these pathogens [14], others argue that the conventional format for some PCRs is more sensitive than the multiplex [35], which may have contributed, at least in part, to some false negatives obtained with mPCR in our study.

Finally, the positive results obtained by serology and PCR in individuals without CAP require a better definition of the role of the causative microorganisms in the respiratory microbiome of these subjects and of the usefulness of this serological test as the gold standard. Both M. pneumoniae and C. pneumoniae are bacteria that are known to colonize the respiratory tract [18-20]. Recent studies show the presence of $M$. pneumoniae and $C$. pneumoniae in asymptomatic individuals (by culture, serology, or detection of DNA). Therefore, detection of these pathogens by PCR does not necessarily indicate disease, and such studies make it clear that none of the methods currently used for diagnosis make it possible to differentiate the carrier state of symptomatic infection [18-20]. It is possible that because many infections caused by these pathogens are asymptomatic, some of the patients without CAP who served as controls may have been recently infected by the pathogens without developing the disease [36], which potentially helps explain the serology conversions observed in these individuals. 
In addition, in 2010, Villegas et al. claimed that $C$. pneumoniae serology can give false positives due to crossreactions in cases of acute infection because of the presence of heterotypic antibodies [37]. A similar phenomenon can be observed with $M$. pneumoniae, whose acute infections are often characterized by the transient generation of autoantibodies, which are considered responsible for many of their extrapulmonary manifestations, and, as shown by our results, some patients with autoimmune diseases may yield false positive results.

In this study, Speed-oligo for L. pneumophila was positive in four patients with rheumatic diseases, whereas mPCR was positive in one of those cases. Although the carrier state for this germ has not been described, several possible explanations exist for this finding. Either people were colonized or were at risk of becoming ill because of the bacteria [38, 39], or these results were false positives of the PCRs, results that cannot be attributed to crosscontamination with other samples as the extraction controls and amplification of PCRs were always negative.

One limitation of the study was the absence of cultures as a gold standard for diagnosis, particularly because such cultures may help to clear up discordant cases. Another possible limitation was that to complete the sample size, we had to resort to various groups of patients (adults and children admitted prospectively and retrospectively). Although these groups were analyzed separately and we were able to evaluate how the tests behaved among themselves in different samples and different populations, the sample size per group was low. Further studies that prospectively evaluate these aspects are required.

\section{Conclusions}

This study demonstrates that the molecular tests (inhouse and commercial) and the reference tests evaluated for the diagnosis of atypical bacteria in patients with CAP have low sensitivity, and do not allow discrimination between those patients with acute or convalescent infection and asymptomatic carriers. Thus, the development of better techniques is needed for the diagnosis of CAP caused by M. pneumoniae, C. pneumoniae, and $L$. pneumophila. Such studies should include prospective evaluations of different sample types and molecular targets, quantification of bacterial DNA, pediatric populations and healthy adults, individuals with suspected CAP infection by these microorganisms, immunocompetent and immunocompromised individuals, and different molecular techniques.

\section{Methods}

\section{Standardization of $\mathrm{mPCR}$}

DNA from M. pneumoniae strain FH of Eaton Agent (gene $p 1$ ), C. pneumoniae strain CM-1 (gene PstI), and
L. pneumophila strain Philadelphia-1 (gene mip) from the American Type Culture Collection (ATCC Virginia, USA) was used for the standardization of $\mathrm{mPCR}$, according to the protocol and primers described by McDonough et al. [40] (Additional file 2). The specificity of the primers was verified using the BLAST program, and the tendency to form homo- and heterodimers, in addition to secondary structures, was evaluated using the Oligo Analyzer program (IDT Technologies, www.idtdna.com/calc/analyzer). The optimal concentrations of the PCR reagents were experimentally determined: primers $(0.2-1.0 \mu \mathrm{M})$, Taq polymerase $(0.05-0.3 \mathrm{U} / \mu \mathrm{L})$, Magnesium chloride (1.0-2.5 $\mathrm{mM}$ ), and bovine serum albumin (BSA $(0.1-0.7 \mu \mathrm{g} / \mu \mathrm{L})$ as adjuvant. The best annealing temperature was selected by performing a temperature gradient between $55^{\circ} \mathrm{C}$ and $66^{\circ} \mathrm{C}$; in addition, primer annealing and extension were evaluated between 30 and $60 \mathrm{~s}$. The optimal conditions were selected according to the points to achieve the sharpness of banding with the lowest DNA concentration.

PCR reactions were revealed using $2 \%$ agarose gel electrophoresis (AMRESCO ${ }^{\circ}$, USA), stained with EZ-VISION $^{\text {ma }}$ (AMRESCO ${ }^{\circ}$, USA); the gel was run at $70 \mathrm{~V}$ for $50 \mathrm{~min}$. Gel images were obtained using the ChemiDoc XRS (BioRad) equipment and the Quantity One ${ }^{\bullet}$ program.

\section{Determination of analytical sensitivity and specificity}

The determination of analytical sensitivity was performed using serial dilutions of DNA from the strains obtained from ATCC or with plasmids containing genespecific inserts. Each amplified fragment was ligated to the pGEM $^{\circ}$-Teasy plasmid (Promega ${ }^{\circ}$, Southampton, USA) according to the manufacturer's instructions. Then, the recombinant plasmids were purified using the Wizard $^{\circledR}$ plus SV Miniprep DNA Purification System (Promega ${ }^{\circ}$, Southampton, USA), linearized and quantified using NanoDrop. The number of copies was calculated from the obtained nanograms [41, 42], and serial dilutions were made. Analytical specificity was evaluated with DNA from different sources at a concentration of $4 \mathrm{ng} / \mu \mathrm{L}$. We evaluated human DNA from peripheral blood cells and DNA from pathogenic and frequent colonizers of the respiratory tract. These colonizers included the bacteria Streptococcus pneumoniae, Staphylococcus aureus, Haemophilus influenzae, Escherichia coli, Enterobacter cloacae, Mycobacterium tuberculosis, Nocardia spp., Klebsiella pneumoniae ATCC10031 and Pseudomonas aeruginosa ATCC PA01 and the fungi Candida albicans, Candida tropicalis, Candida guilliermondii, Candida glabrata, Histoplasma capsulatum, Cryptococcus neoformans, Aspergillus terreus, and Paracoccidioides brasiliensis. A dilution corresponding to 750 copies of each gene was used to evaluate reproducibility. Furthermore, 
mPCR was run six times in one day to determine intraassay reproducibility and on six different days to verify inter-assay reproducibility.

\section{Validation of multiplex PCR}

To validate the mPCR technique, a sample size of 188 patients with CAP was calculated, taking into account an expected sensitivity of $92 \%$ for $\mathrm{mPCR}$, a prevalence of CAP in the city caused by these three atypical bacteria of $24.4 \%$, and a confidence level of $92 \%$. All patients had to be hospitalized.

\section{Study population}

The population consisted of four study groups; the first three groups involved patients hospitalized with CAP who were not severely immunosuppressed. Group 1 consisted of 68 patients who were prospectively enrolled for this study, whereas the patients in group $2(n=88)$ and $3(n=49)$ were taken from two previous studies conducted by our group. Positive cases were selected by quadrupling the titers for these atypical bacteria, and the patients with CAP caused by other pathogens or of unknown etiology were selected randomly until the estimated sample size was attained. The fourth group included individuals without pneumonia (controls) and was divided into two subgroups of equal numbers of patients. One subgroup consisted of blood donors who were completely healthy; the other included patients with rheumatic diseases who were at a higher risk of false positive reactions in paired serology (Table 4).

\section{Ethics, consent and permissions}

All individuals who met the inclusion criteria for the four groups signed an informed consent form in which they agreed to participate. For children, the consent form was signed by the parents or caregivers. Additionally, all children over six also signed the consent form. This study was approved by the Ethics Committee of the School of Medicine at the Universidad de Antioquia (Approval bylaws of the ethics committee: 017 of November 2011, 040 of May 2003 and 005 of May 2011) and by the Ethics Committee of participating institutions: E.S.E. Metrosalud Unidad Hospitalaria San Javier, Clínica Infantil Santa Ana, Clínica Sagrado Corazón, Clínica León XIII, Hospital Universitario San Vicente Fundación, Hospital General de Medellín, Hospital Pablo Tobón Uribe, Clínica Las Américas, Hospital San Rafael de Itagüí, Clínica CES, Hospital Marco Fidel Suárez, Clínica SOMA and Hospital Manuel Uribe Ángel.

\section{Clinical samples and data collection}

Blood, urine, and respiratory secretion samples were taken from all patients at the time of enrollment. According to the established protocol for each study group, the NPSs of groups 1 and 4 were stored at $-20{ }^{\circ} \mathrm{C}$, whereas the NPAs of Group 2 and the NPSs and IS of group 3 were stored at $-80{ }^{\circ} \mathrm{C}$ until processing. Blood samples were taken again between four and eight weeks after capture for convalescent-phase serologic testing.

\section{Antibodies and antigen-based detection methods}

All individuals included in this study underwent the following microbiological tests for the diagnosis of atypical bacteria (following the manufacturer's instructions):

- Detection of antibodies in acute and convalescent serum: total antibodies for L. pneumophila (serogroups 1 to 6, IFI Kits FOCUS Diagnostics ${ }^{\oplus}$ Cypress, CA, USA), IgM and IgG antibodies for $M$. pneumoniae (EIA Pneumobact IgM and IgG VIRCELL ${ }^{\oplus}$, Granada, Spain), and IgG antibodies for C. pneumoniae (Micro-IFI IgG FOCUS Diagnostics ${ }^{\oplus}$, Cypress, CA, USA).

- Urinary antigen for L. Pneumophila, serogroup 1: performed with concentrated urine (Binax NOW Legionella Urinary Antigen Test, Scarborough, ME, USA).

\section{PCR-based molecular diagnosis}

Each sample was evaluated using at least two different molecular tests; one was standardized MPCR, which was performed on all samples; the second test was performed using at least one of the two commercial kits to employ a similar, standardized, and validated technique to allow comparison with mPCR. Speed-oligo ${ }^{\circ}$ (VIRCELL, Granada, Spain) was used in the NPAs or NPSs of groups 1, 2 and 4, and Seeplex PneumoBacter ACE detection (Seegene, Seoul, Korea) was used in the IS of Group 3 (Table 4).

For PCR testing, between 300 and $500 \mu \mathrm{l}$ of the samples were used for DNA extraction. These respiratory samples were thawed and homogenized by vortex for $5 \mathrm{~min}$, centrifuged for $10 \mathrm{~min}$ at $10,000 \mathrm{rpm}$, and the supernatant was discarded. DNA was extracted using the DNeasy ${ }^{\odot}$ Blood \& Tissue Kit (QIAGEN ${ }^{\oplus}$, Hilden, Germany) and quantified using a NanoDrop ${ }^{\star}$ (Thermo Scientific). The total DNA volume added to the reaction was $6 \mu \mathrm{L}$ (which we considered to be optimal after evaluating different volumes between 3 and $8 \mu \mathrm{L}$ ). The DNA concentration was not standardized. Additionally, the presence of inhibitors was ruled out amplifying the $\beta$-globin gen.

All samples were coded and processed blindly to avoid selection and information bias.

\section{Data analysis}

For data analysis, a database was generated using Access ${ }^{\odot}$ and was subjected to quality control prior to analysis. 
Table 4 Eligibility criteria of the study population

\begin{tabular}{|c|c|c|c|c|}
\hline & Group $1(n=68)$ & Group $2(n=88)$ & Group $3(n=49)$ & Group $4(n=20)$ \\
\hline Recruitment & $\begin{array}{l}\text { Prospective, recruited from } \\
2010 \text { to } 2012\end{array}$ & $\begin{array}{l}\text { Retrospective, recruited from } \\
2005 \text { to } 2006 \text {. }\end{array}$ & $\begin{array}{l}\text { Prospective, recruited from } \\
2011 \text { to } 2012\end{array}$ & $\begin{array}{l}\text { Prospective, recruited from } \\
2011 \text { to } 2012\end{array}$ \\
\hline Inclusion Criteria & $\begin{array}{l}\text { 1. Adults } \geq 18 \text { years } \\
\text { 2. Hospitalized with CAP, with } \\
\text { radiologic evidence } \\
\text { 3. Agreed to participate in the study } \\
\text { 4. Available NPS, urine, and blood } \\
\text { samples }\end{array}$ & $\begin{array}{l}\text { 1. Patients } \geq 18 \text { years } \\
\text { 2. Hospitalized with CAP, with } \\
\text { radiologic evidence } \\
\text { 3. Agreed to participate in the } \\
\text { study }\end{array}$ & $\begin{array}{l}\text { 1. Children between } 1 \text { month } \\
\text { and } 17 \text { years } \\
\text { 2. Hospitalized with CAP, with } \\
\text { radiologic evidence } \\
\text { 3. Agreed to participate in the } \\
\text { study } \\
\text { 4. Under } 15 \text { days of symptoms }\end{array}$ & $\begin{array}{l}\text { 1. Adults } \geq 18 \text { years } \\
\text { 2. Agreed to participate in } \\
\text { the study } \\
\text { 3. Completely healthy, } \\
\text { recruited from blood banks, } \\
\text { or individuals with rheumatic } \\
\text { conditions, without respiratory } \\
\text { infection, who could be receiving } \\
\text { tumor necrosis factor antagonists } \\
\text { (anti-TNF) }\end{array}$ \\
\hline Exclusion Criteria & $\begin{array}{l}\text { 1. Hospitalization during the } 2 \text { weeks } \\
\text { prior to recruitment } \\
\text { 2. Obstructive pneumonia due to } \\
\text { lung cancer } \\
\text { 3. Had received antibiotics for over } \\
72 \text { continuous hours at the time of } \\
\text { admission } \\
\text { 4. Severely immunocompromised by: } \\
\text { - Steroid treatment (prednisone } \\
\geq 0.3 \mathrm{mg} / \mathrm{kg} / \text { day for } 3 \text { weeks or more } \\
\text { or } \geq 1 \mathrm{mg} / \mathrm{kg} / \text { day for } \geq 7 \text { days; if using } \\
\text { other steroids, an equivalent dose was } \\
\text { considered) } \\
\text { - Treatment with cytostatics (except } \\
\text { low doses of methotrexate: } \\
\leq 15 \mathrm{mg} / \text { week), } 5 \text {. AlDS diagnosis, } \\
\text { lymphocyte count CD } 4+<200 / \mathrm{mm}^{3} \\
\text { in patients over } 5 \text { years of age or less } \\
\text { than } 15 \% \text { of patients under } 5 \\
\text { granulocytopenia }<500 / \mathrm{mm}^{3} \text {, or } \\
\text { hematologic neoplasia. }\end{array}$ & $\begin{array}{l}\text { 1. Hospitalization during the } \\
2 \text { weeks prior to recruitment } \\
\text { 2. Obstructive pneumonia due } \\
\text { to lung cancer } \\
\text { 3. Severely immunocompromised by: } \\
\text { - Steroid treatment (prednisone } \\
\geq 0.3 \mathrm{mg} / \mathrm{kg} / \text { day for } 3 \text { weeks or more } \\
\text { or } \geq 1 \mathrm{mg} / \mathrm{kg} / \text { day for } \geq 7 \text { days; if using } \\
\text { other steroids, an equivalent dose was } \\
\text { considered) } \\
\text { - Treatment with cytostatics (except } \\
\text { low doses of methotrexate: } \\
\leq 15 \mathrm{mg} / \text { week), } \\
\text { - AlDS diagnosis, lymphocyte count } \\
\text { CD4+<200/mm in patients over } \\
5 \text { years or less than } 15 \% \text { patients } \\
\text { under } 5 \\
\text { - granulocytopenia }<500 / \mathrm{mm}^{3} \text { or } \\
\text { hematologic neoplasia. }\end{array}$ & $\begin{array}{l}\text { 1. Hospitalization during the } \\
2 \text { weeks prior to recruitment } \\
\text { 2. Primary immunodeficiency or } \\
\text { severe acquired immunodeficiency } \\
\text { 3. Cystic fibrosis4. Neurological } \\
\text { alterations (cerebral palsy or } \\
\text { neuromuscular disorders) or } \\
\text { psychiatric alterations that kept } \\
\text { the individual from signing the } \\
\text { consent form,5. Inborn errors of } \\
\text { metabolism,6. Bronchiolitis in } \\
\text { children under } 27 \text {. Hematologic } \\
\text { neoplasia, } 8 \text {. Granulocytopenia } \\
<500 \text { cell/mm39. Non-infectious } \\
\text { chronic neumopathy10. Had AlDS } \\
\text { or lymphocyte count CD4 }<15 \% \\
\text { in children under } 5 \text { years } 11 . \\
\text { Individuals currently being treated } \\
\text { with: } \\
\text { - High-dose steroids (prednisone } \\
\geq 0.3 \text { mg/kg/day for } 3 \text { weeks or } \\
\text { more, or } \geq 1 \text { mg/kg/day for } \\
\geq 7 \text { days; if using other steroids, } \\
\text { an equivalent dose was considered) } \\
\text { - Treatment with cytostatics } 12 \text {. } \\
\text { Had received antibiotics for over } \\
72 \text { continuous hours at time of } \\
\text { admission }\end{array}$ & $\begin{array}{l}\text { 1. Respiratory infections in the } \\
\text { last month } \\
\text { 2. Hospitalization during the } \\
\text { 2 weeks prior to recruitment } \\
\text { 3. Healthcare workers } \\
\text { 4. Heart disease or chronic lung } \\
\text { diseases } \\
\text { 5. Cancer, granulocytopenia, or } \\
\text { infection by HIV/AIDS } \\
\text { 6. Individuals currently being treated } \\
\text { with: } \\
\text { • High-dose steroids (prednisone } \\
\geq 0.3 \mathrm{mg} / \mathrm{kg} / \text { day for } 3 \text { weeks or more } \\
\text { or } \geq 1 \mathrm{mg} / \mathrm{kg} / \text { day for } \geq 7 \text { days; if using } \\
\text { other steroids, an equivalent dose was } \\
\text { considered) } \\
\text { - Treatment with cytostatics } \\
\text { - methotrexate with doses } \\
>15 \mathrm{mg} / \text { week7. Had received } \\
\text { antibiotics for over } 72 \text { continuous } \\
\text { hours at time of admission }\end{array}$ \\
\hline Sample Type & NPS & NPA stored at $-80^{\circ} \mathrm{C}$ & NPS and IS & NPS \\
\hline Commercial PCR used & Speed-Oligo ${ }^{\oplus}$ & Speed-oligo ${ }^{\oplus}$ & Seeplex ${ }^{\circledast}$ Pneumobacter & Speed-Oligo ${ }^{\circledast}$ \\
\hline
\end{tabular}


Statistical analyses were performed using SPSS, version 21.0. Frequency distributions were used to describe the sociodemographic and clinical characteristics of the $L$. pneumophila, M. pneumoniae, or C. pneumoniae cases identified. Sensitivity, specificity, positive and negative predictive value of $\mathrm{mPCR}$, Speed-oligo ${ }^{\circ}$, and Seeplex ${ }^{\circ}$ PneumoBacter were determined using the Epidat 3.1 program. Quadruplicate antibody titers and/or urinary antigen were used as a gold standard test. In addition, the concordance among the molecular techniques (mPCR, Speed-oligo ${ }^{\circ}$ and Seeplex ${ }^{\circ}$ PneumoBacter), between these techniques and serology, and between the different samples was evaluated using the Cohen kappa test.

\section{Additional files}

\section{Additional file 1: Nucleic acid amplification techniques and samples} used for atypical bacteria detection. (DOCX $39 \mathrm{~kb}$ )

Additional file 2: The mPCR primers used for the amplification of M. pneumoniae, L. pneumophila and C. pneumoniae. (DOCX $13 \mathrm{~kb}$ )

\section{Abbreviations}

BAL: bronchoalveolar lavage; CAP: community-acquired pneumonia; IS: induced sputum; mPCR: multiplex PCR; NPA: nasopharyngeal aspirate; NPS: nasopharyngeal swab.

\section{Competing interests}

The authors declare that they have no conflicts of interest. No relation exists with the commercial firm that produces or distributes the serology or PCR tests for the detection of atypical bacteria, and no financial, academic or personal interest exists, directly or indirectly, that may call into question the validity of what is reported. This study was funded by Fundación Rodrigo Arroyave, Universidad de Antioquia, and Fundación Investigando en Salud y Enfermedades Infecciosas, and the Universidad de Antioquia, through the Estrategia de Sostenibilidad CODI 2013-2014.

\section{Authors' contributions}

$\mathrm{MH}$ and YAA conducted the laboratory tests. $\mathrm{MH}$ drafted the manuscript. $\mathrm{CM}$ participated in the design of the study and in the molecular interpretation and development of multiplex PCR. YAA, ZVR, and LAV conceived the study; participated in its design, coordination, and data analysis; and helped to draft the manuscript. All authors read and approved the final manuscript.

\section{Authors' information}

MH: Microbiologist, Master's student in Basic Sciences with an emphasis in microbiology and parasitology. YAA: Bacteriologist, PhD student in Basic Sciences with emphasis in microbiology and parasitology. ZVR: MD, PhD in Epidemiology, Research Department, School of Medicine, Universidad Pontificia Bolivariana. CM: Bacteriologist, MSc in Microbiology and Parasitology, PhD in Basic Science, Coordinator Molecular Biology and Computational Unit, Programa de Estudio y Control de Enfermedades Tropicales (PECET), School of Medicine, Universidad de Antioquia. LAV: MD, specialist in Internal medicine and Infectious Diseases, Department of Internal Medicine, School of Medicine, Universidad de Antioquia.

\section{Acknowledgments}

Thanks to Fundación Rodrigo Arroyave, Universidad de Antioquia, and Fundación Investigando en Salud y Enfermedades Infecciosas for funding the study. Thanks to Clínica SOMA, IPS Universitaria sede Leon XIII, Hospital Universitario San Vicente Fundación - institutions where the prospective patients were recruited.

Thanks to the Corporación para Investigaciones Biológicas, the Clinical Laboratory at Hospital Universitario San Vicente Fundación and the School of Microbiology of the Universidad de Antioquia for providing clinical isolates of bacteria and fungi to determine the analytical specificity of $\mathrm{MPCR}$.

\section{Author details}

Grupo Investigador de Problemas en Enfermedades Infecciosas (GRIPE), Sede de Investigación Universitaria, Calle 62 \# 52-59, Laboratorio 630, Universidad de Antioquia, Medellín, Colombia. ${ }^{2}$ Corporación de Ciencias Básicas Biomédicas, Universidad de Antioquia UdeA, Medellín, Colombia. ${ }^{3}$ Universidad Pontificia Bolivariana, Medellín, Colombia. ${ }^{4}$ Programa de Estudio y Control de Enfermedades Tropicales (PECET), Universidad de Antioquia UdeA, Medellín, Colombia. ${ }^{5}$ Infectious Disease Section, School of Medicine, Universidad de Antioquia UdeA, Medellín, Colombia.

Received: 30 September 2015 Accepted: 5 February 2016 Published online: 02 March 2016

\section{References}

1. Donalisio MR, Arca CHM, de Madureira PR. Clinical, epidemiological, and etiological profile of inpatients with community-acquired pneumonia at a general hospital in the Sumaré microregion of Brazil. J Bras Pneumol Publicaçăo Of Soc Bras Pneumol E Tisilogia. 2011;37:200-8.

2. Irfan M, Faroogi J, Hasan R. Community-acquired pneumonia. Curr Opin Pulm Med. 2013;19:198-208

3. Luna CM, Famiglietti A, Absi R, Videla AJ, Nogueira FJ, Fuenzalida AD, et al. Community-acquired pneumonia: etiology, epidemiology, and outcome at a teaching hospital in Argentina. Chest. 2000;118:1344-54.

4. Díaz A, Barria P, Niederman M, Restrepo Ml, Dreyse J, Fuentes G, et al. Etiology of community-acquired pneumonia in hospitalized patients in chile: the increasing prevalence of respiratory viruses among classic pathogens. Chest. 2007;131:779-87.

5. Fields BS, Benson RF, Besser RE. Legionella and Legionnaires' disease: 25 years of investigation. Clin Microbiol Rev. 2002;15:506-26.

6. Loens $\mathrm{K}$, Goossens $\mathrm{H}$, leven M. Acute respiratory infection due to Mycoplasma pneumoniae: current status of diagnostic methods. Eur J Clin Microbiol Infect Dis Off Publ Eur Soc Clin Microbiol. 2010;29:1055-69.

7. Burillo A, Bouza E. Chlamydophila pneumoniae. Infect Dis Clin North Am. 2010;24:61-71.

8. Plouffe JF. Importance of atypical pathogens of community-acquired pneumonia. Clin Infect Dis Off Publ Infect Dis Soc Am. 2000;31 Suppl 2:S35-9.

9. Ginevra C, Barranger C, Ros A, Mory O, Stephan J-L, Freymuth F, et al. Development and evaluation of Chlamylege, a new commercial test allowing simultaneous detection and identification of Legionella, Chlamydophila pneumoniae, and Mycoplasma pneumoniae in clinical respiratory specimens by multiplex PCR. J Clin Microbiol. 2005;43:3247-54.

10. Park J, Kim JK, Rheem I, Kim J. Evaluation of Seeplex Pneumobacter multiplex PCR kit for the detection of respiratory bacterial pathogens in pediatric patients. Korean J Lab Med. 2009;29:307-13.

11. Thurman KA, Warner AK, Cowart KC, Benitez AJ, Winchell JM. Detection of Mycoplasma pneumoniae, Chlamydia pneumoniae, and Legionella spp. in clinical specimens using a single-tube multiplex real-time PCR assay. Diagn Microbiol Infect Dis. 2011;70:1-9.

12. leven M. Currently used nucleic acid amplification tests for the detection of viruses and atypicals in acute respiratory infections. J Clin Virol Off Publ Pan Am Soc Clin Virol. 2007;40:259-76.

13. Higgins RR, Lombos E, Tang P, Rohoman K, Maki A, Brown S, et al. Verification of the ProPneumo-1 assay for the simultaneous detection of Mycoplasma pneumoniae and Chlamydophila pneumoniae in clinical respiratory specimens. Ann Clin Microbiol Antimicrob. 2009;8:10.

14. Pignanelli S, Shurdhi A, Delucca F, Donati M. Simultaneous use of direct and indirect diagnostic techniques in atypical respiratory infections from Chlamydophila pneumoniae and Mycoplasma pneumoniae. J Clin Lab Anal. 2009;23:206-9.

15. Blanco S, Fuenzalida L, Bas A, Prat C, Ramírez A, Matas L, et al. Comparison of 2 molecular assays and a serologic test in diagnosing Mycoplasma pneumoniae infection in paediatrics patients. Diagn Microbiol Infect Dis. 2011;71:463-6.

16. Qasem JA, Khan ZU, Shiji G, Mustafa AS. Polymerase chain reaction as a sensitive and rapid method for specific detection of Mycoplasma pneumoniae in clinical samples. Microbiol Res. 2002;157:77-82.

17. Templeton KE, Scheltinga SA, Graffelman AW, Van Schie JM, Crielaard $J W$, Sillekens $P$, et al. Comparison and evaluation of real-time PCR, real-time nucleic acid sequence-based amplification, conventional PCR, and serology for diagnosis of Mycoplasma pneumoniae. J Clin Microbiol. 2003;41:4366-71. 
18. Hyman CL, Roblin PM, Gaydos CA, Quinn TC, Schachter J, Hammerschlag MR. Prevalence of asymptomatic nasopharyngeal carriage of Chlamydia pneumoniae in subjectively healthy adults: assessment by polymerase chain reaction-enzyme immunoassay and culture. Clin Infect Dis Off Publ Infect Dis Soc Am. 1995;20:1174-8.

19. Schmidt SM, Müller CE, Krechting M, Wiersbitzky H, Gürtler L, Wiersbitzky SKW. Chlamydia pneumoniae carriage and infection in hospitalized children with respiratory tract diseases. Infection. 2003;31:410-6.

20. Spuesens EBM, Fraaij PLA, Visser EG, Hoogenboezem T, Hop WCJ, van Adrichem LNA, et al. Carriage of Mycoplasma pneumoniae in the upper respiratory tract of symptomatic and asymptomatic children: an observational study. PLoS Med. 2013;10:e1001444.

21. Martínez MA, Ruiz M, Zunino E, Luchsinger $V$, Avendaño LF. Detection of Mycoplasma pneumoniae in adult community-acquired pneumonia by PCR and serology. J Med Microbiol. 2008;57:1491-5.

22. Loens K, Beck T, Ursi D, Overdijk M, Sillekens P, Goossens H, et al. Evaluation of different nucleic acid amplification techniques for the detection of $\mathrm{M}$. pneumoniae, C. pneumoniae and Legionella spp. in respiratory specimens from patients with community-acquired pneumonia. J Microbiol Methods. 2008;73:257-62.

23. Loens K, Van Heirstraeten L, Malhotra-Kumar S, Goossens H, leven M. Optimal sampling sites and methods for detection of pathogens possibly causing community-acquired lower respiratory tract infections. J Clin Microbiol. 2009;47:21-31.

24. Cho M-C, Kim H, An D, Lee M, Noh S-A, Kim M-N, et al. Comparison of sputum and nasopharyngeal swab specimens for molecular diagnosis of Mycoplasma pneumoniae, Chlamydophila pneumoniae, and Legionella pneumophila. Ann Lab Med. 2012;32:133-8.

25. Räty $R$, Rönkkö $E$, Kleemola M. Sample type is crucial to the diagnosis of Mycoplasma pneumoniae pneumonia by PCR. J Med Microbiol. 2005;54(Pt 3):287-91.

26. Reznikov M, Blackmore TK, Finlay-Jones JJ, Gordon DL. Comparison of nasopharyngeal aspirates and throat swab specimens in a polymerase chain reaction-based test for Mycoplasma pneumoniae. Eur J Clin Microbiol Infect Dis Off Publ Eur Soc Clin Microbiol. 1995;14:58-61.

27. Collier AM, Clyde WA. Appearance of Mycoplasma pneumoniae in lungs of experimentally infected hamsters and sputum from patients with natural disease. Am Rev Respir Dis. 1974;110:765-73.

28. Kenny GE, Kaiser GG, Cooney MK, Foy HM. Diagnosis of Mycoplasma pneumoniae pneumonia: sensitivities and specificities of serology with lipid antigen and isolation of the organism on soy peptone medium for identification of infections. J Clin Microbiol. 1990;28:2087-93.

29. Waites KB, Talkington DF. Mycoplasma pneumoniae and its role as a human pathogen. Clin Microbiol Rev. 2004;17:697-728. table of contents.

30. Weiskopf D, Weinberger B, Grubeck-Loebenstein B. The aging of the immune system. Transpl Int Off J Eur Soc Organ Transplant. 2009;22:1041-50.

31. Ginaldi L, De Martinis M, D'Ostilio A, Marini L, Loreto MF, Corsi MP, et al. The immune system in the elderly: I. Specific humoral immunity. Immunol Res. 1999;20:101-8

32. Chaudhry R, Sharma S, Javed S, Passi K, Dey AB, Malhotra P. Molecular detection of Mycoplasma pneumoniae by quantitative real-time PCR in patients with community acquired pneumonia. Indian J Med Res. 2013;138:244-51.

33. Murdoch DR. Nucleic acid amplification tests for the diagnosis of pneumonia. Clin Infect Dis Off Publ Infect Dis Soc Am. 2003;36:1162-70.

34. Schmitt BH, Sloan LM, Patel R. Real-time PCR detection of Mycoplasma pneumoniae in respiratory specimens. Diagn Microbiol Infect Dis. 2013;77:202-5

35. Diaz MH, Winchell JM. Detection of Mycoplasma pneumoniae and Chlamydophila pneumoniae directly from respiratory clinical specimens using a rapid real-time polymerase chain reaction assay. Diagn Microbiol Infect Dis. 2012;73:278-80.

36. Hyman CL, Augenbraun MH, Roblin PM, Schachter J, Hammerschlag MR. Asymptomatic respiratory tract infection with Chlamydia pneumoniae TWAR. J Clin Microbiol. 1991;29:2082-3.

37. Villegas E, Sorlózano A, Gutiérrez J. Serological diagnosis of Chlamydia pneumoniae infection: limitations and perspectives. J Med Microbiol. 2010;59(Pt 11):1267-74.
38. Mariette X, Gottenberg J-E, Ravaud P, Combe B. Registries in rheumatoid arthritis and autoimmune diseases: data from the French registries. Rheumatol Oxf Engl. 2011;50:222-9.

39. Marrie TJ, Bezanson G, Haldane DJ, Burbridge S. Colonisation of the respiratory tract with Legionella pneumophila for 63 days before the onset of pneumonia. J Infect. 1992;24:81-6.

40. McDonough EA, Barrozo CP, Russell KL, Metzgar D. A multiplex PCR for detection of Mycoplasma pneumoniae, Chlamydophila pneumoniae, Legionella pneumophila, and Bordetella pertussis in clinical specimens. Mol Cell Probes. 2005;19:314-22.

41. Calculations: Converting from nanograms to copy number. [http://www. idtdna.com/pages/decoded/decoded-articles/pipet-tips/decoded/2013/10/ 21/calculations-converting-from-nanograms-to-copy-number]. Accessed 12 February 2016.

42. Creating Standard Curves with Genomic DNA or Plasmid Templates for use in Quantitative PCR - quant_pcr.pdf [http://www6.appliedbiosystems.com/ support/tutorials/pdf/quant_pcr.pdf]. Accessed 12 February 2016.

\section{Submit your next manuscript to BioMed Central and we will help you at every step:}

- We accept pre-submission inquiries

- Our selector tool helps you to find the most relevant journal

- We provide round the clock customer support

- Convenient online submission

- Thorough peer review

- Inclusion in PubMed and all major indexing services

- Maximum visibility for your research

Submit your manuscript at www.biomedcentral.com/submit
Biomed Central 